\title{
ANALISIS SPASIAL TINGKAT EROSI TANAH DI DAS CILIWUNG HULU
}

\author{
Nuraida \\ Program Studi Teknologi Industri Pertanian, Fakultas Pertanian Universitas Almuslim \\ Nuraida2727@gmail.com
}

\begin{abstract}
Abstrak
Berkurangnya luasan kawasan hutan yang dijadikan lahan pertanian dan pemukiman di bagian Hulu DAS menyebabkan terjadinya kerusakan sumberdaya alam dan menurunkan fungsi-fungsi hidrologi yang ada di dalam kawasan DAS, seperti meningkatnya lahan kritis, erosi, longsor, dan menurunnya kualitas air sungai. Permasalahan erosi di DAS Ciliwung Hulu salah satunya diakibatkan oleh berkurangnya luasan maupun menurunnya kualitas hutan. Melihat semakin tinggi tingkat kerusakan lingkungan dalam kawasan DAS tersebut, diperlukan suatu upaya/tindakan untuk mencegah semakin tingginya permasalahn erosi. Upaya tersebut dapat dilakukan dengan cara memprediksi tingkat erosi dan memetakan tingkat erosi yang terjadi di kawasan DAS Ciliwung Hulu, sehingga dapat ditentukan pengelolaan yang sesuai untuk setiap kawasan DAS tersebut. Prediski tingkat erosi dengan menggunakan USLE serta sebarannya menggunakan ArcGIS. Penelitian dilakukan di DAS Ciliwung Hulu pada Juni sampai November 2015. Hasil penelitian menunjukkan bahwa kawasan DAS Ciliwung Hulu telah mengalami erosi dari tingkat Sangat rendah sampai sangat berat. Kawasan dengan kriteria Erosi berat dan sangat berat menunjukkan bahwa kawasan tersebut diperlukan suatu tindakan pengolahan tanah untuk mencegah erosi semakin tinggi.

Kata Kunci: Erosi, USLE, Tingkat Erosi, Spasial
\end{abstract}

\section{Pendahuluan}

Berkurangnya luasan kawasan hutan yang dijadikan lahan pertanian dan pemukiman di bagian Hulu DAS menyebabkan terjadinya kerusakan sumberdaya alam dan menurunkan fungsifungsi hidrologi yang ada di dalam kawasan DAS, seperti meningkatnya lahan kritis, erosi, longsor, dan menurunnya kualitas air sungai (Sinukaban, 2007). Kawasan hutan yang berfungsi sebagai daerah tangkapan air, pengendali banjir, erosi, longsor dan sedimentasi telah dikonversi menjadi lahan pertanian dan pemukiman mengakibatkan degradasi lahan di DAS Ciliwung Hulu.

Permasalahan erosi di DAS Ciliwung Hulu salah satunya diakibatkan oleh berkurangnya luasan maupun menurunnya kualitas hutan. Secara kumulatif laju erosi yang terjadi di DAS Ciliwung Hulu sebesar 19,3 ton/ha/thn, dengan indeks erosi sebesar 1,29 (>1) yang berarti bahwa DAS tersebut tergolong tidak baik ditinjau dari segi erosi (KLH, 2003). Suryadi, 2011 menyatakan bahwa 53,98\% dari seluruh luas DAS Ciliwung Hulu memiliki potensi erosi normal-rendah, palingluas terjadi di Sub DAS Ciliwung Hulu. Potensi erosi beratsangat berat mencakup $31,61 \%$ dari total luas wilayah dab terbesar di Sub DAS Cibogo Cisarua.

Faktor utama yang terlibat dalam proses terjadinya erosi adalah iklim, sifat tanah, topografi dan vegetasi penutup lahan. Wischmeier dan Smith (1975) menyatakan 
bahwa factor-faktor tersebut dimanfaatkan sebagai dasar untuk menentukan besarnya erosi tanah melalui persamaan umum yang kemudian lebih dikenal dengan sebutan persamaan universal (Universal Soil Loss Equation/USLE).

Melihat semakin tinggi tingkat kerusakan lingkungan dalam suatu kawasan DAS yang diakibatkan oleh pengelolaan hutan yang tidak berkelanjutan, mengindikasikan perlu dilakukannya suatu tindakan untuk mengatasi permasalahan dan memperbaiki pengelolaan hutan. Upaya/tindakan tersebut dapat dilakukan dengan cara memetakan tingkat erosi yang terjadi di kawasan DAS Ciliwung Hulu, sehingga dapat ditentukan pengelolaan yang sesuai untuk setiap kawasan DAS tersebut.

Adapun tujuan dari penelitian ini yaitu: 1) Mengetahui tingkat erosi tanah berdasarkan faktor penyebab erosi yang terjadi di DAS Ciliwung Hulu menggunakan metode USLE; 2) Mengetahui sebaran tingkat erosi tanah di DAS Ciliwung Hulu.

\section{Metodologi Penelitian}

\section{Tempat dan Waktu}

Penelitian ini dilakukan di DAS Ciliwung Hulu yang terletak pada koordinat $106^{0} 50^{\prime} 50^{\prime \prime}-107^{0} 00^{\prime} 40^{\prime \prime}$ BT dan 6036'10"$6^{0} 47^{\prime} 00^{\prime \prime}$ LS. Sebagian besar DAS Ciliwung Hulu berada di wilayah Kabupaten Bogor (30 desa) sisanya sebagian kecil berada di wilayah Kota Bogor (1 Kelurahan). Penelitian dilakukan mulai bulan Mei sampai November 2015.

\section{Bahan dan Alat}

Alat yang digunakan dalam penelitian ini yaitu perlengkapan pengambilan sampel tanah (ring sampel, pisau lapang, plastik, kertas label, meteran), alat tulis, kamera digital, Global Positioning System (GPS), buku panduan pengamatan lapangan serta software ArcGis.

Bahan yang digunakan dalam penelitian ini berupa data-data sekunder yang diperlukan untuk prediksi erosi yaitu berupa data spasial (peta dasar dan tematik) dan data non spasial (data dan laporan hasil penelitian, laporan statistik) yang diperoleh dari studi kepustakaan.

\section{Pengumpulan Data}

Penelitian dimulai dari tahap prapenelitian, dengan melakukan kajian atas data sekunder baik di perpustakaan umum, ataupun instansi terkait dengan pengelolaan DAS Ciliwung Hulu, yaitu: Balai Pendayagunaan Sumberdaya Air (BPSDA) Ciliwung-Cisadane, Badan Pengelolaan Daerah Aliran Sungai dan Hutan Lindung (BPDASHLS) Citarum-Ciliwung dan melakukan survey lapang di DAS Ciliwung Hulu.

Pengambilan sampel tanah dilakukan dengan metode simple random sampling, sampel tanah diambil pada 9 (sembilan) titik berdasarkan peta satuan tanah. Pada tiap jenis tanah diambil 3 contoh tanah utuh sehingga keseluruhan sebanyak 27 sampel tanah, selain tanah utuh juga diambil sampel tanah terganggu sebanyak $500 \mathrm{~g}$ untuk masing-masing sampel. Kemudian sampel tanah dianalisis di laboratorium Ilmu Tanah dan Sumberdaya Lahan, Institut Pertanian Bogor. Tanah dianalisis untuk diketahui kandungan tekstur, C-organik, permeabilitas, Bulk density, dan kadar air.

\section{Pengolahan dan Analisis Data}

Pengolahan data sekunder untuk prediksi erosi menggunakan data yang sudah dikumpulkan pada tahap pengumpulan data. Ground check di lapangan dilakukan setelah 
pengolahan dan pemetaan awal. Pengambilan sampel tanah sebagai data primer untuk menganalisis erosi tanah dilakukan pada saat ground check kawasan DAS Ciliwung Hulu.

Tahapan selanjutnya adalah melakukan analisis lanjutan berdasarkan hasil ground check dan menggunakan data primer untuk mengidentifikasi kawasan yang berpotensi erosi. Pengolahan data kuantitatif menggunakan software berupa ArcGIS. Hasil akhir dari pengolahan data yang dilakukan adalah beberapa variabel yang akan digunakan dalam penelitian ini. Adapun variable tersebut antara lain Tingkat bahaya erosi dan sebaran erosi tanah.

\section{Erosivitas Hujan}

Persamaan USLE menetapkan bahwa nilai $\mathrm{R}$ merupakan daya perusak hujan (erosivitas hujan) tahunan dapat dihitung dari data curah hujan otomatik atau dari data penakar curah hujan biasa. Erosivitas dihitung menggunakan persamaan yang dikembangkan Lenvain (1975) dalam Arsyad (2010) dengan rumus:

dimana:

$$
\mathrm{R}=2.21 \times \mathrm{CH}^{1.36}
$$

$$
\begin{aligned}
& \mathrm{R}=\text { indeks erosivitas hujan bulanan, } \\
& \mathrm{CH}=\text { curah hujan rata-rata bulanan }(\mathrm{cm}) .
\end{aligned}
$$

\section{Erodibilitas Tanah}

Erodibilitas tanah (K) menunjukkan tingkat kepekaan tanah terhadap erosi yaitu mudah tidaknya tanah mengalami erosi. Erodibilitas tanah dipengaruhi oleh tekstur (pasir sangat halus, debu dan liat), struktur tanah, permeabilitas tanah dan kandungan bahan organik tanah. Erodibilitas tanah dihitung dengan persamaan Wischmeier \& Smith (1978) dalam Arsyad (2010) yaitu:

$100 \mathrm{~K}=2.1\left(\mathrm{M}^{1.14}\right)\left(10^{-4}\right)(12-\mathrm{a})+3.25(\mathrm{~b}-2)$ $+2.5(\mathrm{c}-3)$ dimana:

$\mathrm{K}=$ nilai erodibilitas tanah,

$\mathrm{M}=$ ukuran partikel (\%debu + \%pasir sangat halus) x (100 - \%liat), $\mathrm{a}=$ kandungan bahan organik tanah $(\%)$,

$\mathrm{b}=$ kelas struktur tanah

$\mathrm{c}=$ kelas permeabilitas tanah (cm/jam).

\section{Panjang dan Kemiringan Lereng}

Moore \& Burch (1986) dalam Kinnell (2008) telah mengembangkan suatu persamaan untuk mencari nilai LS dengan memanfaatkan data DEM menggunakan SIG. Adapun persamaan yang digunakan adalah:

$$
\begin{gathered}
\mathrm{LS}=\left(\mathrm{X}^{*} \mathrm{CZ} / 22.13\right)^{0.4} *(\sin / 0.0896)^{1.3} \\
\text { dimana: } \\
\mathrm{LS}=\text { Faktor lereng } \\
\mathrm{X}=\text { Akumulasi aliran } \\
\mathrm{CZ}=\text { Ukuran pixel } \\
=\text { Kemiringan lereng }
\end{gathered}
$$

\section{Analisis Spasial Berdasarkan USLE}

Analisis spasial dilakukan dengan menumpangsusunkan (overlay) beberapa data spasial (parameter penentu erosi) dalam bentuk layer untuk menghasilkan unit pemetaan baru yang digunakan sebagai unit analisis yaitu analisis erosi. Pada setiap unit analisis tersebut dilakukan analisis berdasarkan data atribut. Hasil analisis berdasarkan data atribut selanjutnya dikaitkan dengan data spasialnya untuk menghasilkan data spasial perkiraan laju erosi. Perkiraan erosi berdasarkan metode USLE dengan membangun basis data system informasi geografis dengan menggunakan teknik tumpang-susun (overlay) terhadap faktor-faktor erosi sehingga diperoleh suatu lapisan informasi baru mengenai perkiraan erosi yang 
dihasilkan. Untuk mencapai tujuan itu pengolahan data spasial dengan menggunakan teknologi Sistem Informasi Geografis (SIG) memamfaatkan perangkat lunak ArcGIS 10.1.

Proses tumpang-susun ini dilakukan dengan overlay kesemua layer antara lain : erodibilitas tanah, kemiringan lereng dan penggunaan lahan sehingga dihasilkan sebuah peta baru yaitu peta satuan lahan yang kemudian di- overlaykan dengan layer erosivitas curah hujan tahunan rata-rata sehingga dihasilkan layer erosi.

\section{HASIL DAN PEMBAHASAN}

\section{Analisis Parameter Penyebab Erosi Tanah}

Besar kecilnya tingkat erosi tanah dipengaruhi oleh faktor-faktor penyebab erosi. Parameter erosivitas, erodibilitas, kelerengan, pengelolaan tanaman dan tindakan konservasi tanah merupakan lima faktor yang dipertimbangkan dalam prediksi erosi menggunakan metode USLE. Adapun nilai-nilai dari faktor-faktor penyebab erosi tersebut dapat dilihat pada tabel 1 .

Tabel 1 Analisis Faktor penyebab Erosi

\begin{tabular}{cccccc}
\hline No & \multicolumn{5}{c}{ Nilai Faktor } \\
\cline { 2 - 6 } & $\mathrm{R}$ & $\mathrm{K}$ & $\mathrm{LS}$ & $\mathrm{C}$ & $\mathrm{P}$ \\
\hline 1 & 2473.42 & 0.13 & 1.20 & 0.800 & 0.4 \\
2 & 2473.42 & 0.17 & 12.00 & 0.350 & 0.04 \\
3 & 2473.42 & 0.28 & 1.20 & 0.350 & 0.04 \\
4 & 2473.42 & 0.15 & 4.25 & 0.100 & 1.00 \\
5 & 2473.42 & 0.30 & 1.20 & 0.300 & 1.00 \\
6 & 2473.42 & 0.34 & 12.00 & 0.005 & 1.00 \\
7 & 2473.42 & 0.26 & 0.25 & 0.500 & 1.00 \\
8 & 2473.42 & 0.26 & 0.25 & 0.200 & 1.00 \\
9 & 2473.42 & 0.34 & 0.25 & 0.500 & 1.00 \\
\hline
\end{tabular}

Pengolahan data, 2016

\section{Erosivitas Hujan (R)}

Curah hujan merupakan faktor iklim yang sangat berpengaruh terhadap terjadinya erosi. Arsyad (2010) menyatakan bahwa besarnya curah hujan, intensitas, dan distribusi hujan menentukan kekuatan dispersi hujan terhadap tanah, jumlah dan kekuatan aliran permukaan serta tingkat kerusakan erosi yang terjadi. Kawasan DAS Ciliwung Hulu dikenal sebagai daerah yang memiliki intensitas hujan yang tinggi. Hal tersebut dikarenakan sebagian besar DAS Ciliwung Hulu merupakan wilayah perbukitan. Curah hujan diperoleh dari tiga stasiun yang terdapat di lokasi penelitian yaitu Katulampa, Gadog, dan Gunung Mas. Sepanjang tahun 2003 sampai 2012, curah hujan di DAS Ciliwung Hulu sangat bervariasi dengan curah hujan tertinggi tahun 2010 sebesar $3993 \mathrm{~mm}$ dan terendah pada tahun 2011 sebesar $2540 \mathrm{~mm}$.

Hasil perhitungan nilai Erosivitas hujan (R) menggunakan persamaan Lenvain (1975), menunjukkan nilai $\mathrm{R}$ di kawasan DAS Ciliwung hulu sebesar 2473,42 $\mathrm{mm} / \mathrm{thn}$ selama tahun 2003 sampai tahun 2012.

\section{Erodibilitas Tanah (K)}

Berdasarkan peta satuan tanah Kabupaten Bogor skala 1:250 000, kawasan DAS Ciliwung Hulu memiliki 10 (sepuluh) satuan tanah. Klasifikasi tanah yang digunakan adalah sistem Soil Taxonomy (Soil Survey Staf 1992) sampai kategori Sub group (macam tanah). Berdasarkan Peta Tanah Semidetail Tahun 1992 yang dikeluarkan oleh Pusat Penelitian Tanah dan Agroklimat Bogor, jenis tanah di DAS Ciliwung Hulu terdiri dari order Inceptisol, Andosol Ultisol, dan sisanya Entisol. 
Sebaran nilai K di DAS Ciliwung Hulu dapat dilihat pada Gambar 1.

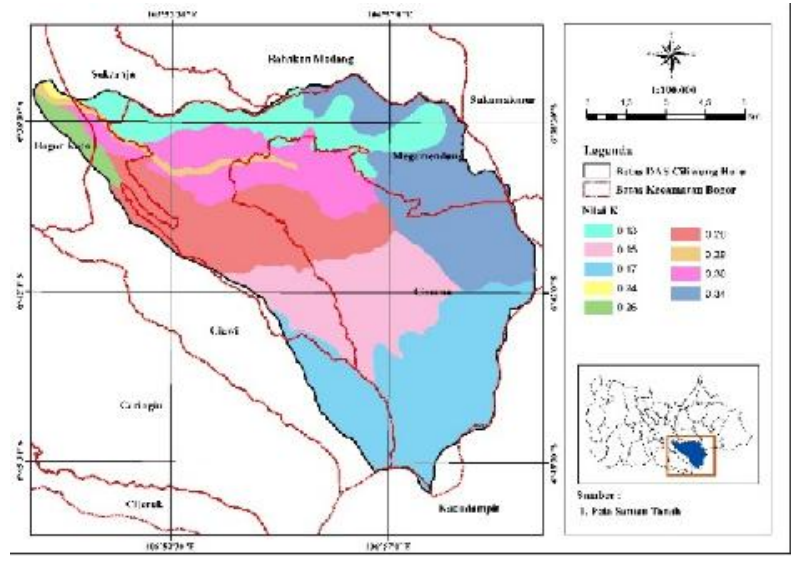

Gambar 1 Sebaran Nilai Erosivitas Tanah

(K)

\section{Panjang dan Kemiringan Lereng (LS)}

Berdasarkan bentuk topografinya, kemiringan lereng wilayah DAS Ciliwung Hulu bervariasi mulai dari datar, landai, agak curam, curam sampai dengan sangat curam. Daerah-daerah dengan topografi curam dan tidak ada/jarang penutup lahan akan memudahkan tanah terdispersi akibat energi kinetik hujan. Peta sebaran kemiringan lereng dapat dilihat pada Gambar 2 berikut.

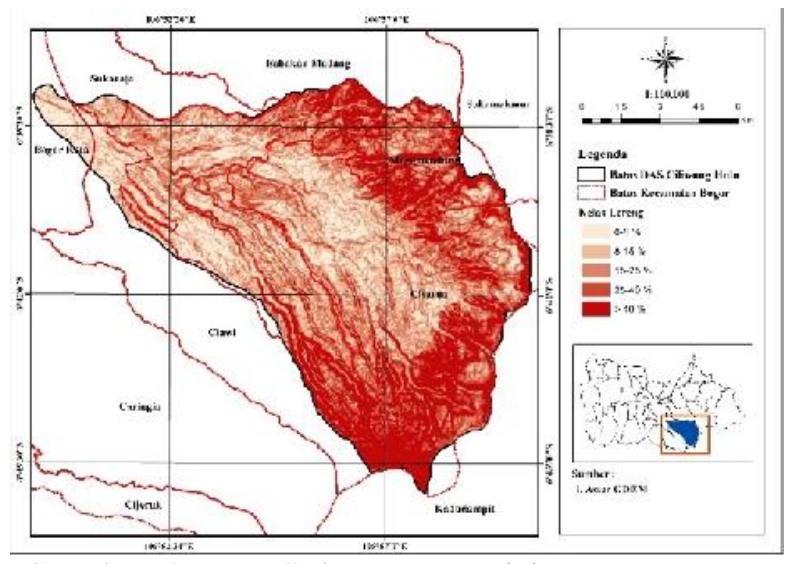

Gambar 2 Peta Sebaran Kemiringan Lereng
Berdasarkan peta penggunaan lahan tahun 2013, penggunaan lahan di DAS Ciliwung Hulu terdiri dari 9 (sembilan) jenis penggunaan lahan meliputi belukar, hutan lahan kering primer, hutan lahan kering sekunder, hutan tanaman, perkebunan, pemukiman, pertanian lahan kering, pertanian lahan kering sekunder, dan tanah terbuka. Sebagian besar didominasi oleh penggunaan lahan berupa hutan tanaman sebesar 4078 ha (27\%) dan pertanian lahan kering sebesar 6512 ha (43\%). Sebaran penggunaan lahan dapat dilihat pada Gambar 3.
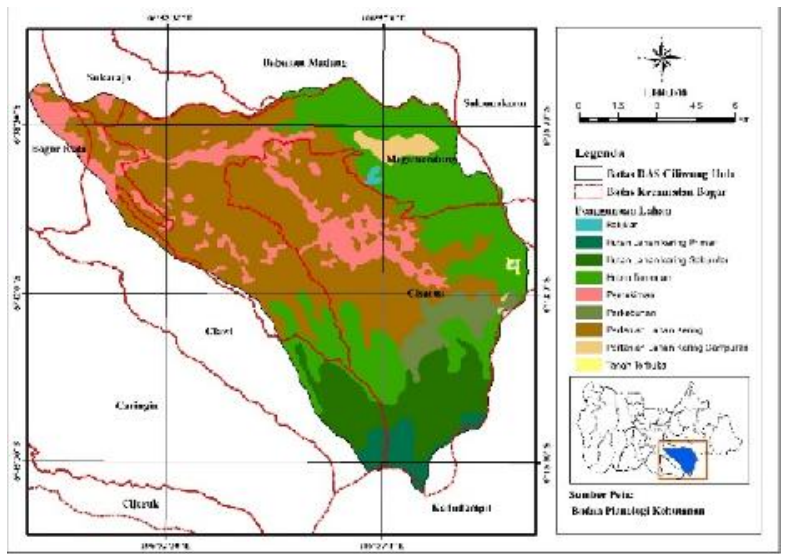

Gambar 3 Sebaran Penggunaan lahan

\section{Prediksi Erosi Tanah}

Tingkat erosi DAS Ciliwung Hulu ditentukan berdasarkan metode Tingkat Erosi Finney dan Morgan (Finney \& Morgan, 1984 dalam Prawijiwuri, 2011) (Tabel 2), sedangkan tingkat bahaya erosi ditentukan berdasarkan atas metode klasifikasi tingkat bahaya erosi (Hammer, 1994 dalam Diara, 2001), dimana tingkat bahaya erosi dipengaruhi oleh kedalaman tanahnya.

\section{Penggunaan Lahan (CP)}


Tabel 2. Tingkat Erosi berdasarkan Metode Tingkat Erosi Finney dan Morgan (Finney \& Morgan, 1984 dalam Prawijiwuri, 2011).

\begin{tabular}{cc}
\hline Erosi Tanah $($ Ton/ha/th) & Tingkat Erosi (Finney \& Morgan) \\
\hline$<15$ & Sangat Rendah \\
$15-60$ & Rendah \\
$60-180$ & Sedang \\
$180-480$ & Berat \\
$>480$ & Sangat Berat
\end{tabular}

DAS dasarkan hasil perhitungan USLE diperoleh sebaran erosi pada kawasan DAS Ciliwung Hulu. Hasil perhitungan bahaya erosi dibedakan dalam 5 kelas bahaya erosi, yaitu kelas I $(<15$ ton/ha/thn), kelas II $(15-60$ ton/ha/thn), kelas III (60-180 ton/ha/thn), kelas IV (180-480 ton/ha/thn) dan kelas V (> 480 ton/ha/thn) dengan luasan masingmasing disajikan pada Tabel 3. Berdasarkan luasannya, DAS Ciliwung Hulu menunjukkan bahwa $17 \%$ dari total luasan

termasuk dalam kelas erosi sangat rendah, $39 \%$ termasuk kelas rendah, 19\% termasuk kelas sedang, $12 \%$ kelas berat dan $13 \%$ kelas sangat berat. Potensi erosi rendah umumnya mendominasi kawasan DAS Ciliwung Hulu sebesar 5868 ton/ha/tahun (39\%) dari total luasan DAS. Sebaran potensi erosi aktual disajikan pada Gambar 4.

Tabel 3. Besaran Erosi Tanah Di DAS Ciliwung Hulu

\begin{tabular}{llccr}
\hline \multirow{2}{*}{ No } & \multirow{2}{*}{ Bahaya Erosi } & ton/ha/thn & \multicolumn{2}{c}{ Luas Potensi Erosi } \\
\cline { 4 - 5 } & & $<15$ & 2570 & $\%$ \\
\hline 1 & Sangat Rendah & $15-60$ & 5868 & 17 \\
2 & Rendah & $60-180$ & 2811 & 39 \\
3 & Sedang & $180-480$ & 1891 & 19 \\
4 & Berat & $>480$ & 2036 & 12 \\
5 & Sangat Berat & & 15173 & 100 \\
\hline
\end{tabular}

Pengolahan Data, 2016

Erosi yang terjadi pada DAS Ciliwung Hulu bervariasi mulai dari sangat rendah sampai sangat berat. Erosi dengan tingkat rendah medominasi wilayah Ciliwung Hulu sebesar 39\% dari total luasan DAS Ciliwung Hulu, diikuti Erosi Sedang
$19 \%$, erosi sangat rendah $17 \%$, erosi Sangat berat $13 \%$ dan erosi berat $12 \%$. Hal ini menunjukkan bahwa DAS Ciliwung Hulu telah terjadi erosi dengan kategori berat dan sangat berat. 


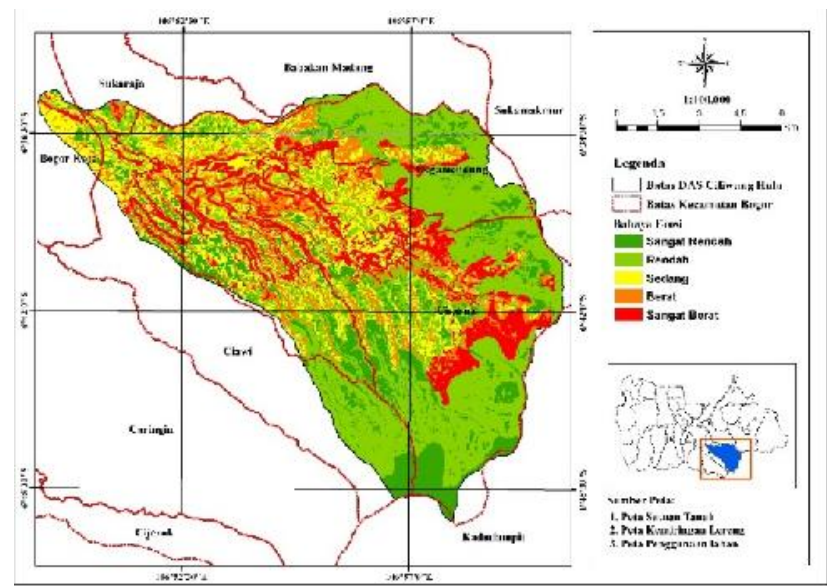

Gambar 4 Sebaran Erosi Tanah DAS

Ciliwung Hulu

Gambar 4 menunjukkan bahwa Potensi erosi menyebar luas pada berbagai kemiringan lereng mulai dari kemiringan 0\% sampai lebih dari $40 \%$ dan tersebar pada berbagai penggunaan lahan. Lahan dengan bahaya erosi berat termasuk kelas IV mengalami potensi erosi seluas 1891 ha $(12 \%)$ dan erosi sangat berat termasuk kelas $\mathrm{V}$ mempunyai sebaran erosi sebesar 2036 ha $(13 \%)$ yang menyebar pada lahan berlereng $0 \%$ sampai lereng lebih dari $40 \%$.

Faktor utama yang menyebabkan erosi berat dan sangat berat adalah penggunaan lahan yang kurang sesuai dengan kondisi topografi lahan. Umumnya DAS Ciliwung Hulu berada pada wilayah yang memiliki topografi curam hingga sangat curam (lereng > 25\%-40\%), maka peluang terjadinya erosi sangat besar terutama jika pengelolaan dilakukan dengan cara-cara yang tidak ramah lingkungan. Dewi et al. (2012) menyatakan bahwa kondisi kemiringan lereng yang curam tanpa dilakukannya tindakan konservasi akan menurunkan kapasitas infiltrasi tanah,memperbesar jumlah aliran permukaan serta kecepatan aliran permukaan, dengan demikian memperbesar energi angkut aliran permukaan dan erosi menjadi berat.
Distribusi potensi erosi kelas sangat rendah sampai rendah sebagian besar ditemukan di kawasan hutan. Hutan merupakan daerah tangkapan air yang berfungsi untuk mengurangi erosi. Perubahan penggunaan lahan meningkatkan jumlah erosi (Fitzpatrick et al. 1999; Wibowo 2005; Murillo et al. 2011; Junaidi et al. 2011; Wijitkosum 2012). Hal ini karena vegetasi penutup tanah memainkan peran penting dalam melindungi permukaan tanah dari dampak air hujan secara langsung, serta menurunkan kecepatan dan volume air limpasan sehingga dapat menahan partikel tanah.

Penggunaan lahan hutan di DAS Ciliwung Hulu didominasi oleh jenis hutan primer, sekunder dan hutan tanaman (Gambar 3) yang berada pada kemiringan lereng > 40\%, hutan di lokasi penelitian memiliki tajuk yang rapat sehingga mampu mengurangi laju air hujan yang jatuh ke permukaan tanah, sehingga ketika air hujan sampai di permukaan tanah maka kekuatan energi kinetik hujan yang menimbulkan erosi akan berkurang dan tidak akan menimbulkan erosi berat. Pada jenis tanah dan kemiringan lereng yang sama, hutan memberikan kontribusi terjadinya erosi lebih kecil dibandingkan dengan lahan pertanian atau semak/belukar.

Hutan memiliki peran penting dalam mengatur sistem air, pengendalian erosi dan sistem pendukung kehidupan manusia. Oleh karena itu, menjaga fungsi hutan dengan mengurangi laju deforestasi dan degradasi hutan sangat penting. Hal ini karena fungsi hidrologis DAS tidak dapat digantikan dengan penggunaan lahan vegetasi selain pohon (Andriyanto 2015). Hutan dengan vegetasi dan penutupan lahan yang rapat mampu mengurangi laju erosi tanah. Bukhari et al. (2015) menyatakan bahwa faktor vegetasi penutup tanah (C) berperan sebagai pelindung tanah terhadap gaya-gaya erosi dengan memperkecil hempasan tetesan 
air hujan, menghambat laju aliran limpasan dan memperbaiki struktur tanah. Dengan mempertimbangkan erosi aktual (dengan faktor CP) juga masih ditemui potensi erosi berat dan sangat berat yang umumnya terjadi pada penggunaan lahan kebun/perkebunan dan tegalan/ladang. Hal ini menunjukkan bahwa pengelolaan lahan di kawasan DAS Ciliwung Hulu telah menyebabkan degradasi lahan.

\section{KESIMPULAN}

Berdasarkan hasil dan pembahasan maka dapaisimpulkan bahwa:

1. DAS Ciliwung Hulu telah mengalami Potensi erosi dari kategor sangat rendah sampai sangat berat.

2. Faktor erosi yang sangat berpengaruh di lokasi penelitan adalah curah hujan tahunan yang tinggi (>2000mm), diikuti penggunaan lahan yang tidak sesuai dengan kemampuan lahan, kemiringan lereng, karakteristik tanah serta pengelolaan lahan kawasan DAS Ciliwung hulu yang menyebabkan degradasi.

\section{DAFTAR PUSTAKA}

Arsyad, S. 2010. Konservasi Tanah dan Air. Bogor: IPB Press.

Andriyanto C, Sudarto, Suprayogo D. 2015. Estimation of soil erosion for a sustainable land use planning: RUSLE model validation by remote sensing data utilization in the Kalikonto watershed. Journal of degraded and mining lands management ISSN: 2339076X, Volume 3, Number 1: 459- 468 DOI:10.15243/jdmlm.2015.031.459.

Bukhari I, Kemala SL, Alida L. 2015.Pendugaan erosi aktual berdasarkan metode USLE melalui pendekatan vegetasi, kemiringan lereng dan erodibilitas di hulu sub DAS Padang. Jurnal Online Agroekoteknologi. ISSN No. 23376597 Vol., No.: 160 - 167.

Dewi I. Utami GAS, Trigunasih NM, Kusmawati T. 2012. Prediksi erosi dan perencanaan konservasi tanah dan air pada Daerah Aliran Sungai Saba. EJurnal Agroekoteknologi Tropika.Vol.1 No. 1.

Fitzpatrick FA, Knox JC. Whitman HE. 1999. Effects of Historical Land-Cover Changes on Flooding and Sedimentation,North Fish Creek, Wisconsin. USGS Water-Resources Investigations Report 99. Wisconsin.

Junaidi E, Tarigan SD. 2011. Pengaruh hutan dalam pengaturan tata air dan proses sedimentasi Daerah Aliran Sungai (DAS):Studi Kasus di DAS Cisadane. Jurnal Penelitian Hutan dan Konservasi Alam 8 (2): 155-176.

Kinnell, P.I.A. 2008. The Miscalculation of the USLE Topographic Factors in GIS. Faculty of Science University of Canberra. Canberra Australia.

[KLH] Kementerian Lingkungan Hidup. 2003. Laporan Status Lingkungan Hidup Tahun 2002. Jakarta (ID).

Murillo JFM, López-Vicente M, Poesen J, Ruiz-Sinoga JD. 2011. Modelling the effects of land use changes on runoff and soil erosion in two mediterranean catchments with active gullies (South of Spain). Landform Analysis 17: 99104.

Sinukaban N. 2007. Pengelolaan daerah aliran sungai. Bahan kuliah. Bogor (ID): Program Pascasarjana. Institut Pertanian Bogor.

Suryadi C. 2011. Wilayah prioritas konservasi tanah dan air di DA Ci 
Liwung Hulu. [tesis]. Depok (ID): Universitas Indonesia.

Prawijiwuri, G. 2011. Model Erosion Hazard Untuk Pengelolaan Sub Daerah

Aliran Sungai (DAS) Cisokan Provinsi Jawa Barat. Tesis. Program Magister Ilmu Lingkungan Program Pasca Sarjana Universitas Diponegoro. Semarang. http://eprints.undip.ac.id/31493/1/tesis. pdf.

Wibowo M. 2005. Analisis pengaruh perubahan penggunaan lahan terhadap debit sungai (studi kasus sub DAS Cikapundung Gandok-Bandung). Jurnal Teknik Lingkungan BP3TLBPPT. 6 (1): 283-290.

Wijitkosum S. 2012. Impacts of land use changes on soil erosion in Pa Deng Sub-district, adjacent area of Kaeng Krachan National Park, Thailand. Journal of Soil and Water Research 7(1): 10-17.

Wischmeier, W.H. and Smith, D. D. 1978. Predicting Rainfall Erosion Losses A Guide to Conservation Planning. USDA Handbook No. 537. Washington DC. 